\title{
Provincial Comparison of Development Status in Nepal: An Analysis of Human Development Trend for 1996 to 2026
}

Sanjib Dhungel

Email: dhungel2011@gmail.com

The present study examines the status of Human Development Index (HDI) for 1996, 2001, 2006 and 2011 for seven provinces of Nepal and projected for 2016, 2021, 2026. Base data are obtained from Nepal Human Development Reports (HDR)1998, 2004, 2009 and 2014. The HDI value for the Province 1, 3, 4 and 5 are relatively higher than national average and that for Province 6 is least followed by Province 2 and Province 7. The largest HDI value for 1996 is 0.499 for Province 1, in 2001 is 0.508 for Province 4, in2006 is 0.558 for Province 3 and in 2011is 0.560 for Province. The estimated value for 2016 is 0.578 for Province 1, 0.60 in 2021. Province 1 will continue to lead with 0.622 in 2026. Meanwhile Province 5 will join the club in 2021. Similarly, the lowest HDI value for 1996 is 0.364 for Province 6 and it is lowest for Province 7, in 2001 with value of 0.364. HDI is 0.44 for Province 6, in 2006, and same province is at the lowest rank with value of 0.463 in 2011. Estimated lowest HDI value for 2016 is 0.486 for Province 6, and it will be 0.509 in 2021, and it will be 0.531 in 2026 for this Province. There is smooth growth on HDI over time i.e. impact of investment for development have positive result in Province 3, Province 4 and Province 6, followed by Province 1 and Province 7. Inconsistent growth is observed in Province 5 and Province 2.

Key words: Human Development, Human Development Index, Province, Estimation, Tempo change/growth and trend

\section{Human development concept and evolution}

The concept of human development was officially adopted by United Nations Development Programme (UNDP) in late 1980s and early 90s. The HDI was used to measure country status in the first Human Development Report 1990. Mahbub U1 Haq and Amartya Sen, well known economist in South Asia, contributed to bring concept of human development in practice. In 
1990, the UNDP transformed the landscape of development theory, measurement, and policy with the publication of its first annual HDR with the introduction of HDI. The HDR 1990 defined "Human Development" as progress towards greater human well-being, and provided country-level data for a comparing country status based on the well-being indicators. The UNDP's efforts to publish the HDR expanded both the availability of measurement and comparison tools to be used by governments, NGOs and researchers, and our common understanding of development (Shanton, 2007).

The Report used three indicators, one from social sector, one from economic sector and one from health sector. Combined index of literacy status and mean age at school is taken as social indicator. Per capita income interms of purchasing parity per person (PPP) is used as economic indicator while life expectancy at birth is used as health indicator as it reflects the situation of reproductive health, basic health and sanitation and hygienic condition of society. This also provides evidence on demographic contexts like fertility level, mortality level, morbidity and survival of everyone. HDI is classified into three range: 0.75 and above as high, 0.5 to below 0.75 as medium and below 0.5 as low human development category (NHDR, 1990).

\section{Nepali context}

\section{Restructuring of Nepal}

The Constitution of Nepal, promulgated on 20 September 2015 federalised Nepal with politically delineated seven Provinces. Each Province (from 1 to 7) containing 14, 8,13,10, 13, 8 and 9 districts respectively. Nawalparasi district is divided into two Provinces- Province4 (eight local units from eastern part) and Province 5 (seven local units from western part) and Rukum is divided into Province 5 ( 3 local units from eastern part) and Province 6 (six local units from western part).

\section{Province wise local units}

Nepal's sub-national governing units are restructured into 753 local units with renewed mandate, which is further classified into 6 Metropolis, 9 Sub-metropolis, 258 municipalities, 458 Rural Municipalities. Province 1 and Province 2 have almost equal number of local units while Province 6 has the least. 


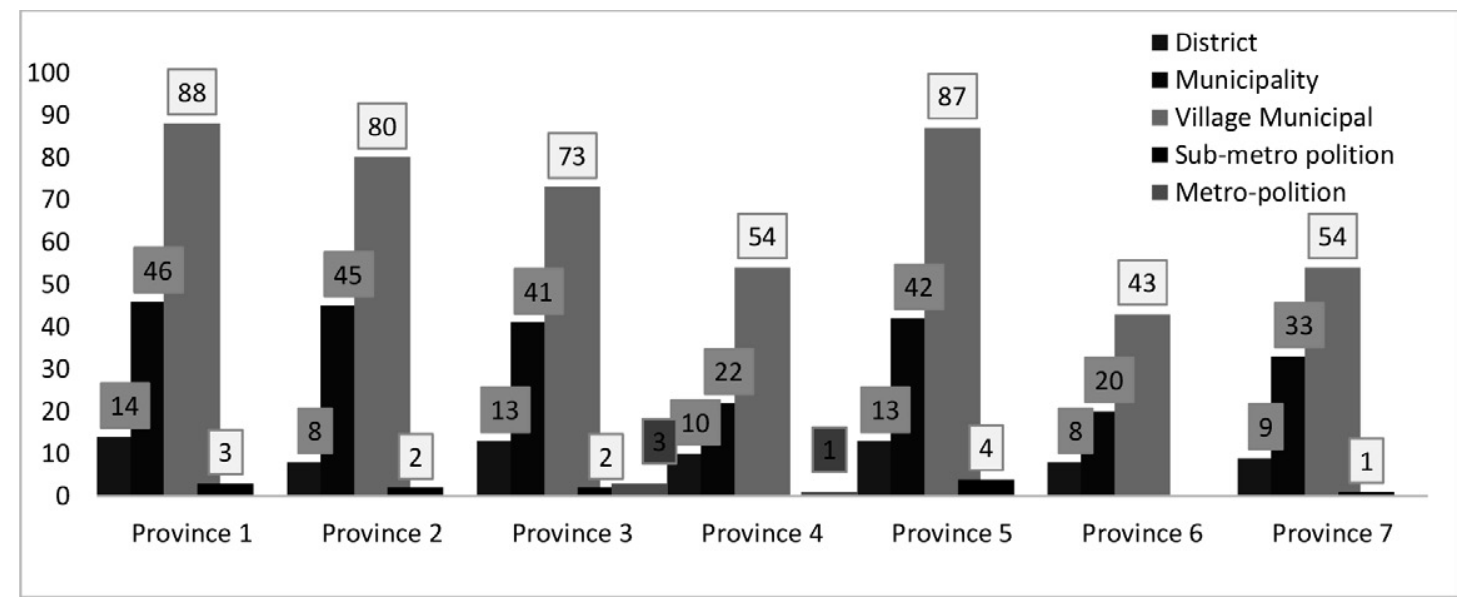

Figure 1: Distribution of local units by Province, Nepal 2018

\section{Objective and method}

Nepal has just embarked into federal system. Most of the literature on HDI in Nepal is available for district and eco-development region or national level. However, the Constitution of Nepal assumes Province as the major governing units between federal and local level where most of the development plans will be based. This requires substantial study at Province level. The present article is an attempt to explore the situation of human development by Province. The HDI is calculated from existing reports of UNDP that provide data at district and eco-development level. Information for this article are based on combined indicator on health, education and income with reference period of 1996, 2000, 2001, 2006 and 2011. An extrapolation is made to estimate HDI for 2016, 2021 and 2026 (Annex 1). This article is expected to encourage researcher, academics, policy maker and development partners to initiate discourse from Provincial perspective of development indicators. The findings may help for Province level planning producing development strategy.

\section{HDI in 1996}

HDI for the period 1996 was significantly influenced by life expectancy index. The value was higher in eastern Nepal and decreases gradually towards west Nepal. All seven Provinces had comparable life expectancy ranging between 48-62 years. The index ranged from 0.612 in Province 1 to 0.385 in Province 7. If we decompose the index at district level, it ranged from as high as 0.7 in Kathmandu to as low as 0.183 in Mugu with mean 0.513 and standard deviation 0.103 . The poor health facilities and low level of socio-economic status are general reasons cited for poor performance of Mugu and alike districts. 


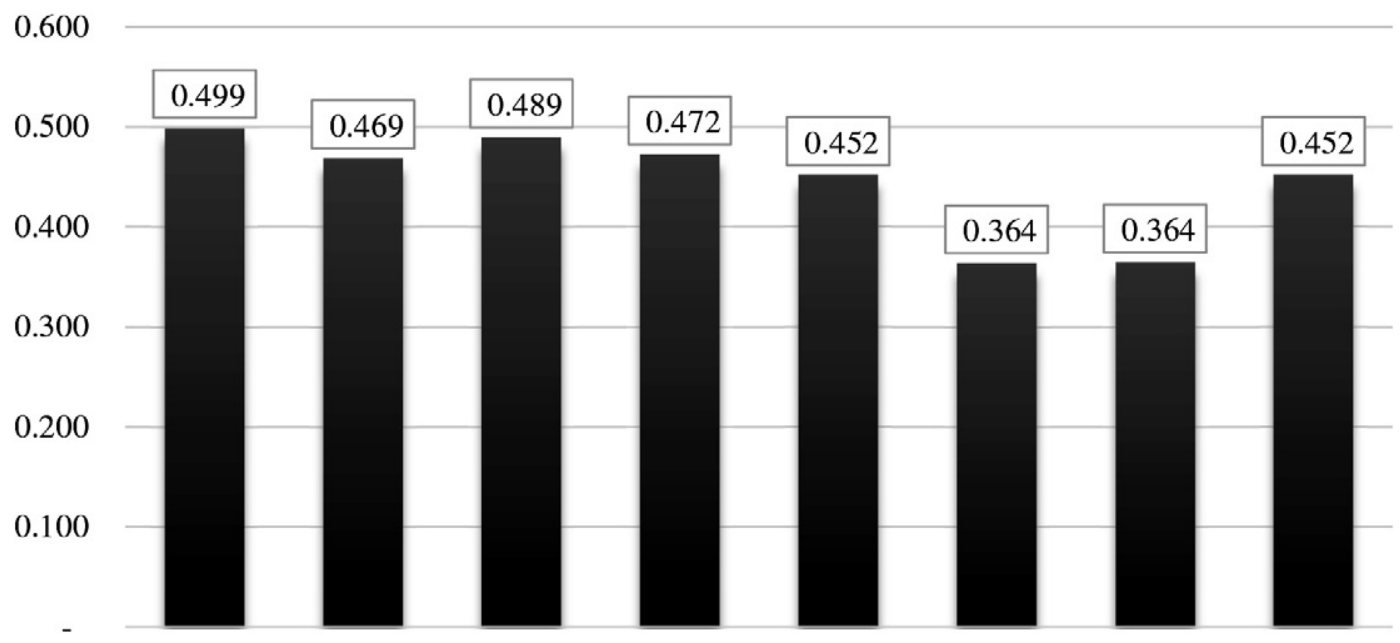

Province 1 Province 2 Province 3 Province 4 Province 5 Province 6 Province 7 National

Figure 2: Provincial comparison of HDI in 1996

With the improvements in health facilities, expansion of education facilities and people's access to economic opportunities contributed to overall improvement in the indices. In 1996, the literacy rate was between 27 percent in Province 6 to 42 percent in Province 1. The education attainment index for the same period ranged between 0.336 in Province 1 to 0.214 in Province 6. Among districts, Kathmandu scored highest value of 0.59 whereas Rasuwa remained at the bottom with 0.122 score. The economic indicator (measured in terms per capita purchasing power parity) was performing even poorly- ranging between the highest value of 0.239 in Province 3 to the lowest value of 0.12 in Province 7. Like education, Kathmandu led with 0.52 whereas Bajura remained at the bottom with 0. 071 (Figure 2).

\section{HDI in 2001}

In 2001, Province 4 reached to medium human development category. Province 3 and Province 1 approached to medium human development while remaining four Provinces (2, 57 and 6) fall far below than nation average. HDI for the period 2001 was largely dependent to improvement in life expectancy index, ranging between 0.660 in Province 1 to 0.482 in Province 6. Among districts, Bhaktapur remained on top with score of 0.772 while Mugu was placed at the bottom with a value of 0.318 . 


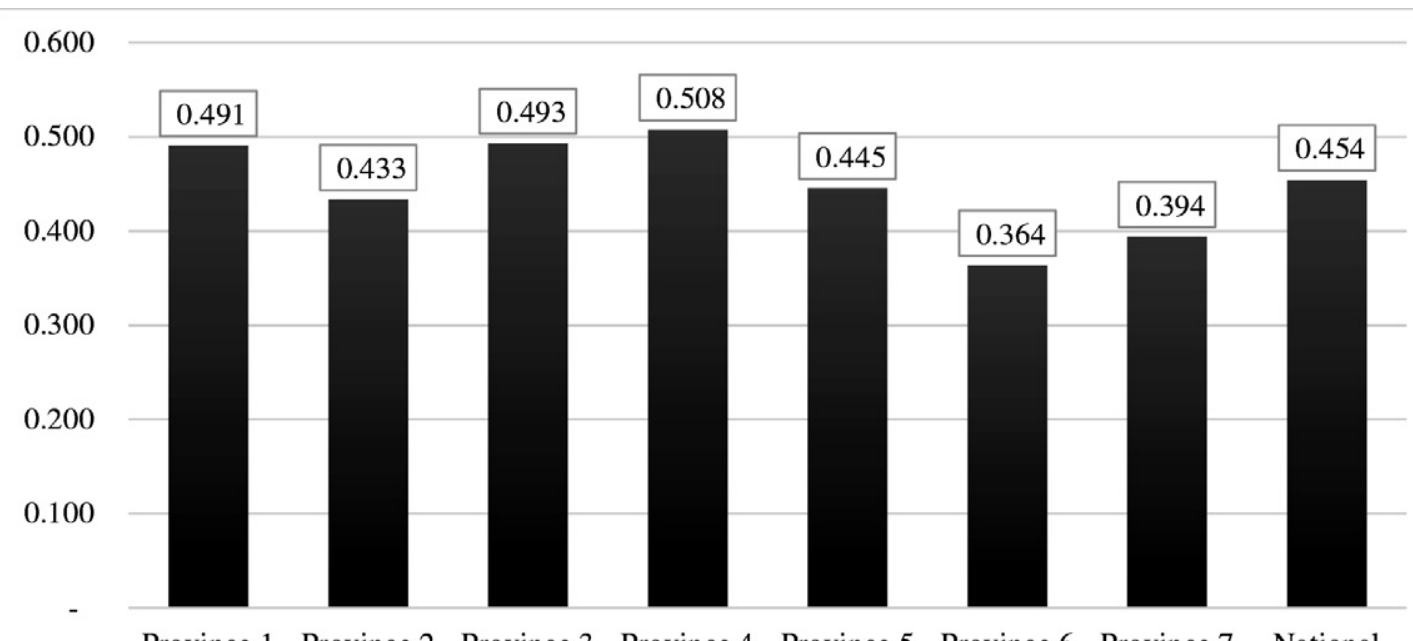

Province 1 Province 2 Province 3 Province 4 Province 5 Province 6 Province 7 National

Figure 3: Provincial comparison of HDI in 2001

Increasing access to public health facility, expansion of health service from private investment and increasing awareness in public health were reasons for improvement in health indicator. The education index ranged between 0.415 in Province 3 to 0.274 in Province 6 . Among districts, Kathmandu remained at the top with a score of 0.622, whereas Humla was pushed to bottom with a value of 0.158 . Despite improvements in literacy rate, the mean years of school could not improve, thereby having negative impact in education index. The access to resource index ranged between 0.452 for Province 3 to 0.382 for Province 6. Kathmandu, again ranked the top with a score of 0.59 whereas Dailkeh remained at the bottom with a score of 0.32 .

\section{HDI in 2006}

In 2006, Province 1, Province 3 and Province 4graduated from low human development and reached to medium human development category while remaining four Provinces $(2,57$ and 6 , respectively) were struggling to graduate, with a large margin from national average. In this period too, improvements in life expectancy seems more dominant for overall improvements in the HDI. Province 3 recorded highest life expectancy value with 0.728(Province 3) while Province 6 scored the lowest 0.509 . The index for education ranged from 0.446 in Province 3 to 0.356 in Province 2. For economic index, Province again performed highest with 0.501 , while Province 7 fell short with 0.431 in provincial comparison. 


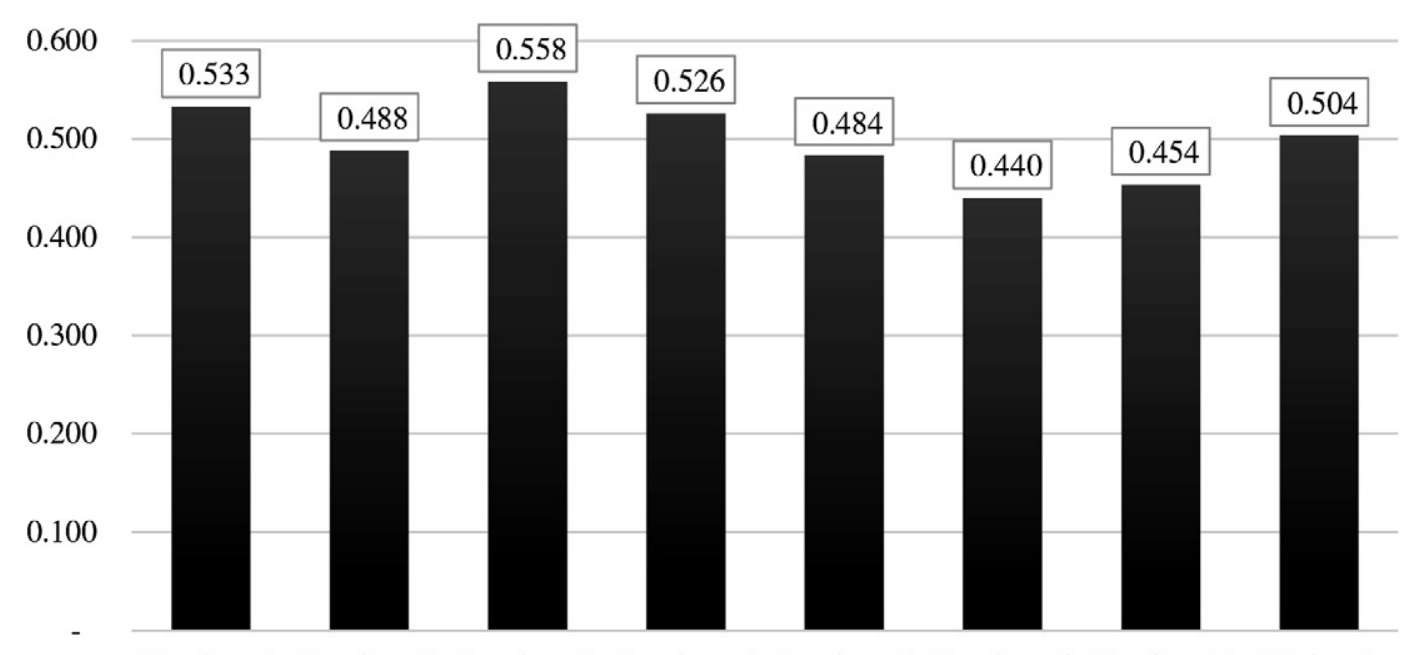

Province 1 Province 2 Province 3 Province 4 Province 5 Province 6 Province 7 National

Figure 4: Provincial comparison of HDI in 2006

\section{HDI in 2011}

By 2011 Province 1, Province 3 and Province 4remained in medium human development with improved performance where as Province 2, Province 5, Province 6 and Province 7 still struggle to graduate to medium level, with just below the national average. The life expectancy index continued to dominate in overall performance. Interestingly, Province 2 made a jump to score top in life expectancy index with a value of 0.757 and Province 6 remained at the bottom with 0.677 . Among districts, Ramechhap came forward with a value of 0.798 and Dolpa at the bottom with a value of 0.603 . Province 2 remained at the bottom for education index with a value of 0.274 while Province 4 scored highest with 0.430 . Kathmandu remained as the best performing district in education with a score of 0.56 whereas Rautahat was at the bottom with a score of 0.226 . Despite improvement in literacy rate, overall performance in education was still not as expected. The economic index could not improve as expected. Province 3 remained at the top but with relatively low score of 0.427 and Province 7 at the bottom with a value of 0.316 . Kathmandu led with 0.554 against Bajhang at the bottom with a value of 0.264 in Bajhang. 


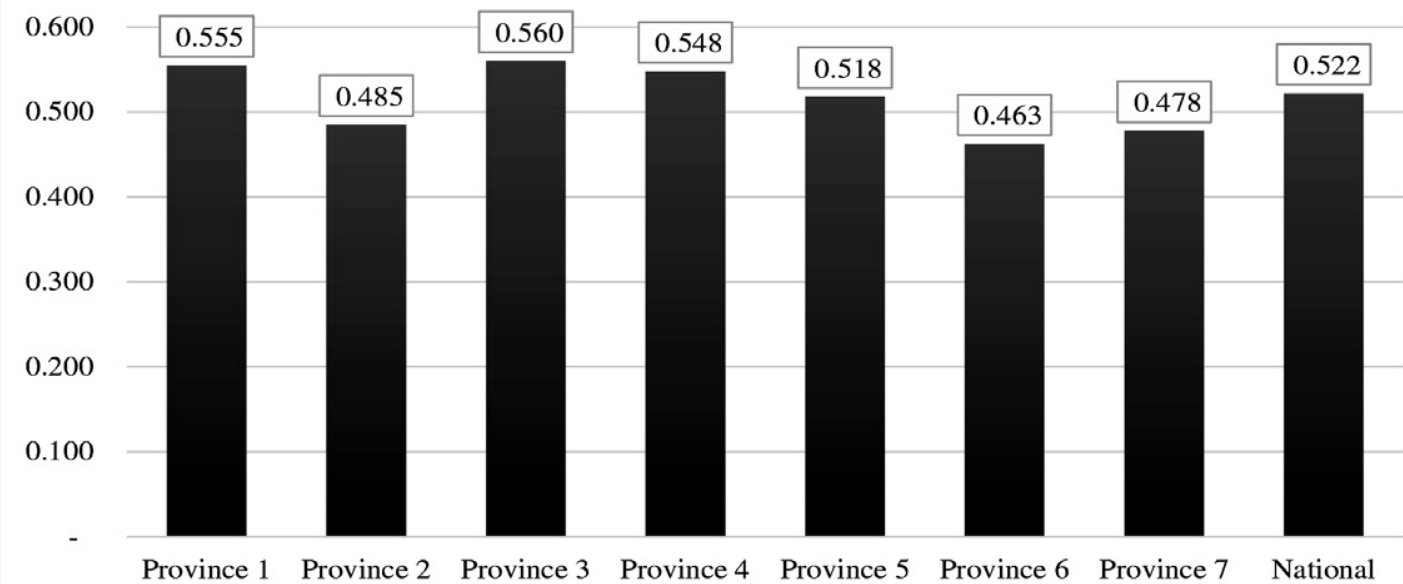

Figure 5: Provincial comparison of HDI in 2011

\section{Trend of HDI from 1996 to 2011}

The rate of change in HDI among Provinces between 1998 and 2011 is not uniform, with a range of 0.35 to 0.6 . For Province 1 , it increased by a magnitude of 0.064 magnitude with overall increment of $13.03 \%$ from 0.491 (2001) to 0.555 (2011). Noticeably, for Province 2 the value of HDI decreased from 0.47 in 1996 to below 0.40 in 2001. It increased thereafter but slowly. In Province5 and 6 HDI increased faster between 2001 and 2011. Province 2, Province 3 made marginal increment in HDI between 2006 and 2011. Province 3 made a huge jump between 2001 and 2006 but remained stagnant thereafter. For Province 6, no difference was observed between 1998 and 2001. The predictability of trend in HDI is better for Province 4 with a $\mathrm{R}^{2}$ value of 0.979 and poor for Province 2 with a value of 0.291 .
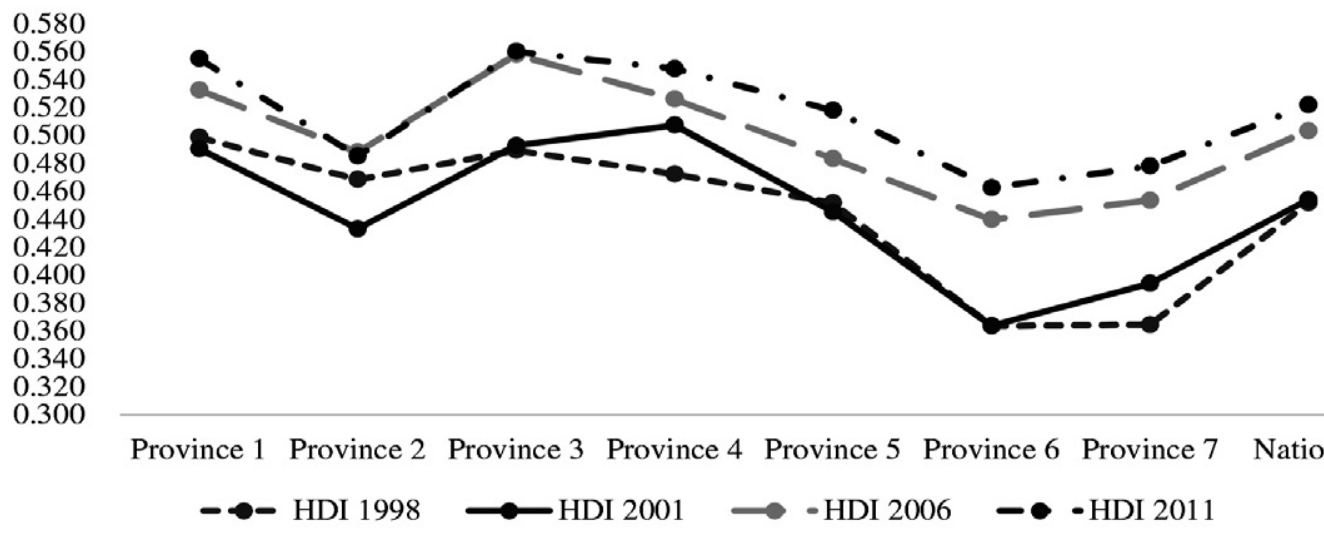

Province 1 Province 2 Province 3 Province 4 Province 5 Province 6 Province 7 National $\multimap-$ HDI $1998 \longrightarrow$ HDI $2001 \longrightarrow$-HDI $2006 \longrightarrow \bullet-H D I 2011$

Figure 6: HDI trend between 1998 and 2011 by Province 


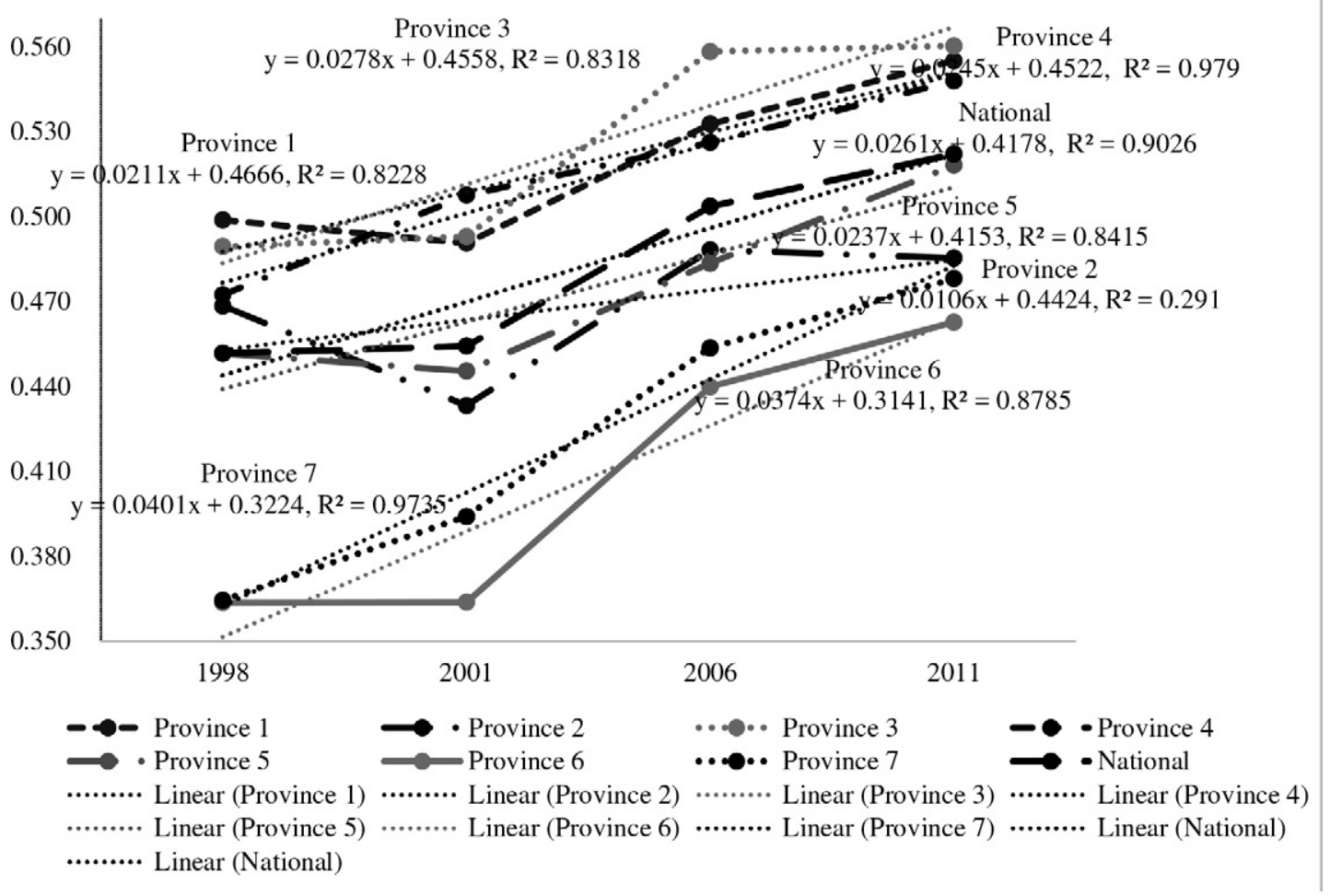

Figure 7: Trend of HDI and regression fit between 1998 and 2011 by Province

Figure 7 provides a basis for predicting future trend of HDI for provinces. If current trend remains true, Province 4 will continue to lead among the Provinces. The steady growths of Province 6 and Province 7 are also noteworthy, but they are below the national average. Trend of Province 2 is not predictable but a growth can be expected in future. Province 1 and Province 3, along with Province 4 can be considered as better performing Provinces as they are above national average. Province 5 is trying to meet national average and can be expected that it will meet soon.

\section{Estimation for 2016, 2021 and 2026}

Based on the trend between 1996 and 2011, HDI for 2016, 2021 and 2026 are estimated. The estimation shows that in 2016 Province 1 holds the highest position with better economic development, improved educational attainment followed by Province 4 leading in economic index. Province 1, Province 3, Province 4 and Province 5 surpass national average and ensure strong presence in medium HDI group. Province 2 and Province 7 reach in border line of medium range while Province lags behind in the comparison in 2016. 


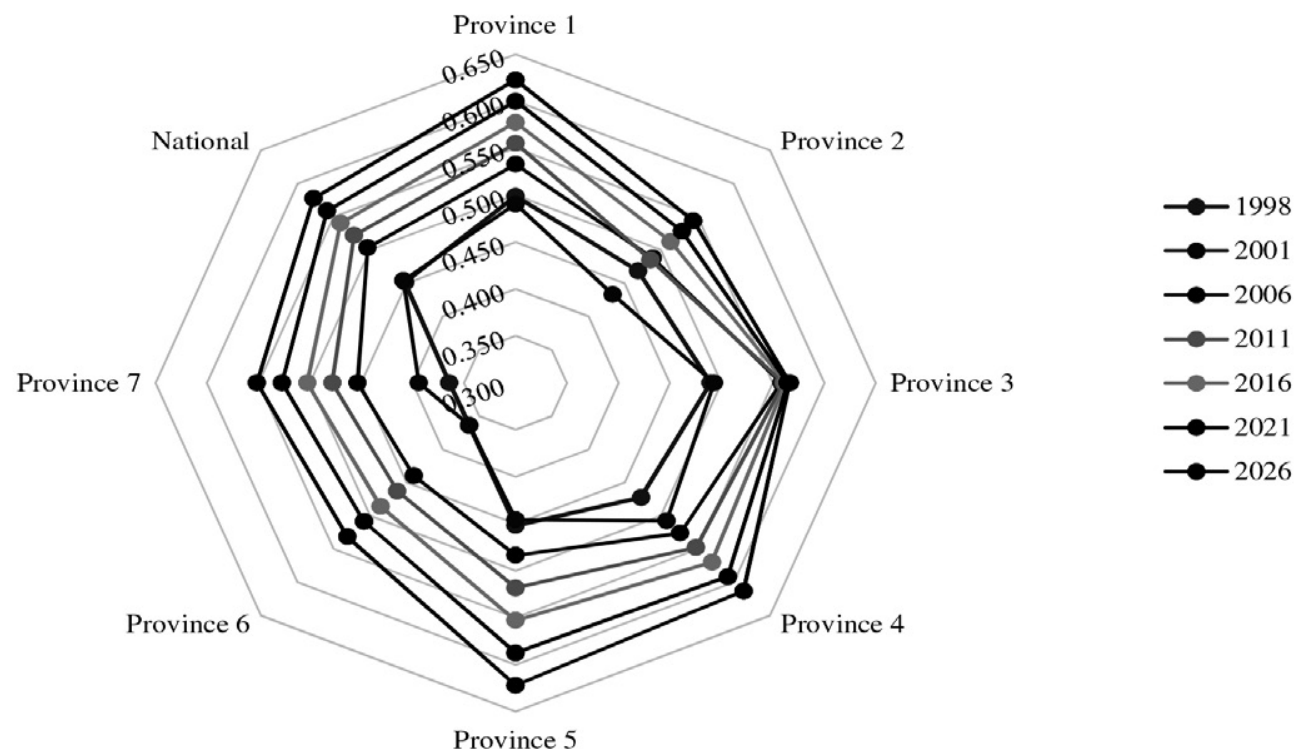

Figure 8: Estimated HDI values for 2016, 2021 and 2026 by province

The estimation shows that by 2021 the national HDI value will be 0.559 and by 2026 it will reach to 0.578 . Province 1 will continue to lead among Provinces, together with Province 4 and Province 5. Province 3 seems more stable throughout the period. Province 2, Province 6 and Province 7 are performing low and will remain below national average but with consistently lowering gap. Province 5 makes significant improvement over the years.

Table 1 shows differential growth patterns on dimensions of human development among Provinces. Between 1996 and 2011, life expectancy and literacy status observed a steady growth over the years. Province 6 and Province 7 witnessed higher annual growth in life expectancy where Province 1 grew slowly. In literacy status, almost all Provinces grew in similar level, Province 6 improved with a higher rate of about 5.44 percent per annum. Province 5, Province 4 and Province 3 also exceeded average national growth of 4.26 percent whereas Province 1, Province 2 and Province 7 were below the national average.

The economic index did not follow uniform trend across Provinces. Only Province 1 and Province 4 witnessed positive change. Province 2 and Province 7 recorded a decline in economic status by 1.9 percent and 1.12 percent per annum, respectively. The reasons are largely associated with limited economic opportunities and increase in market price. Nepal suffered from decade long armed conflict between 1996 and 2006, which reduced economic activities to some urban centres. The contraction of economic activities had a systemic impact in overall performance of country's economic status. However, performance of economic indicator is expected to improve in days to come. 
Table 1: Analysis of HDI between 1996 and 2011

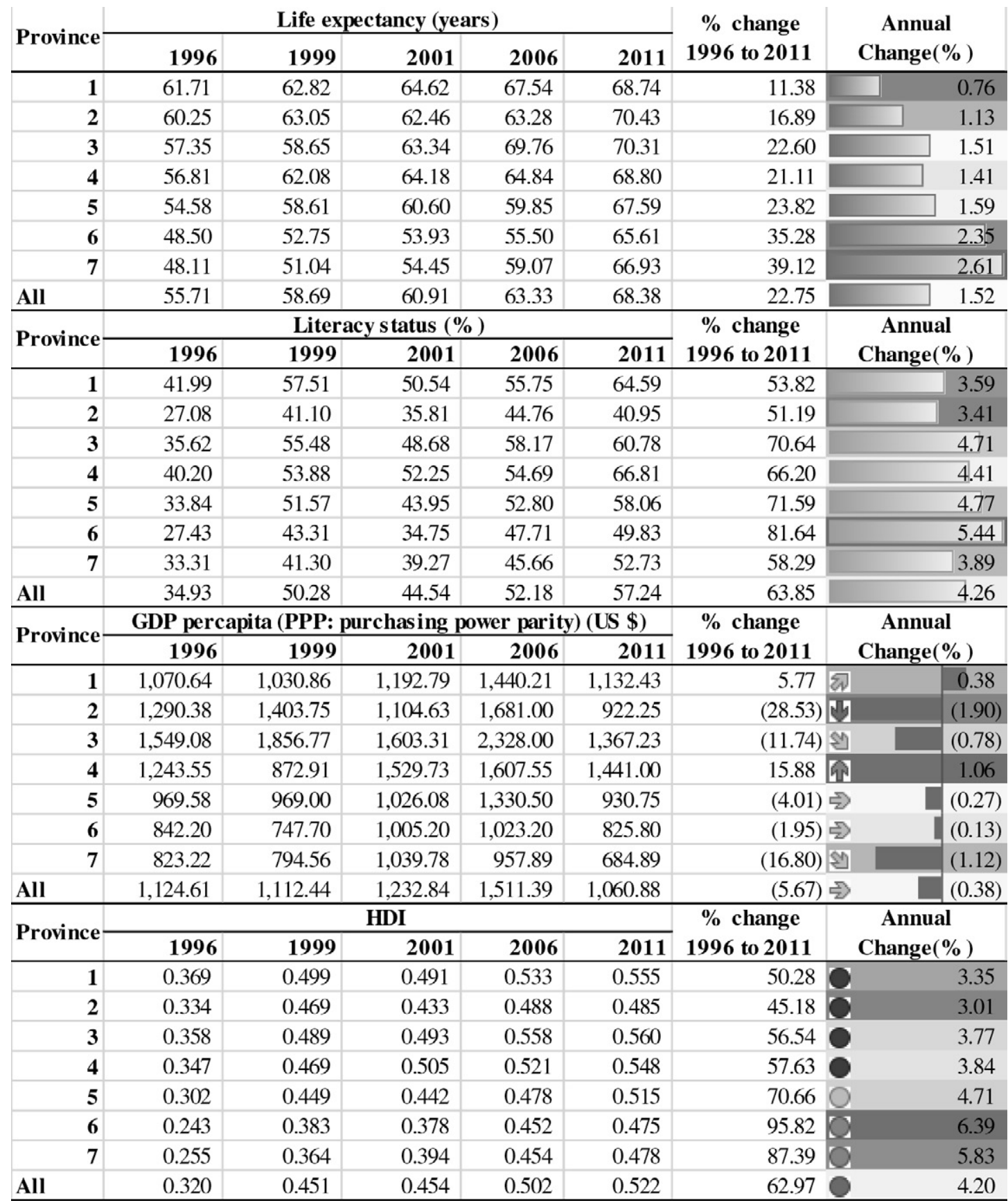

Source: Calculated from Human Development Reports 


\section{Conclusion}

The difference in HDI performance basically depends on level of socio-economic development of the particular area. The differential performance does not follow uniform trend. Some Provinces are performing better in one indicator while rest in other indicators. The HDI value increased from 0.320 (1996) to 0.522 (2011) by a margin of 63.85 percent. Improvement in education/social sector, civic awareness, democracy practices and government investment on health, education and economic development form a base for this improvement. While increasing access of people to economic resources and opportunities, expansion of market activities and foreign employment also have significant contribution for this change. The impact of later factors is expected to be more in the days to come. The contribution of health sector in overall improvement of HDI is also noteworthy, which grew by 22.75 percent. State's investment to ensuring health facilities has been instrumental in improvement of wellbeing. The economic sector's performance was relatively low. Against expectation of improvement, the economic indexed measured in PPP decreased to \$1060 (2011) from \$1125 (1996).

\section{References}

Stanton, E. A. (2007). The human development index: A history. PERI Working Papers85. Massachusetts: University of Massachusetts.

UlHaq, M. (1995). Reflections on human development. London: Oxford University Press.

United Nation Development Programme (UNDP) (1990).Human development report 1990.

New York: UNDP. .(1998). Nepal human development report 1998. Kathmandu: UNDP. (2001). Nepal human development report 2001. Kathmandu: UNDP. .(2004). Nepal human development report 2006. Kathmandu: UNDP. .(2008). Nepal human development report 2007/2008. United Nation New York: UNDP. .(2011). Nepal human development report 2011. Kathmandu: UNDP. .(2014). Nepal human development report 2014. Kathmandu: UNDP. 


\section{Annex 1: HDI Calculation method}

1. Human Development Index

$$
\text { HDI }=\frac{(\text { lifexpectancy index }+ \text { education index }+ \text { percapita index })}{3}
$$

2. Life expectancy index

$$
\mathbf{e}^{0} \operatorname{Index}=\frac{(x-a)}{(b-a)}
$$

3. Education attainment Index

$$
\text { Educational attainment Index }=\frac{(2(\text { adult literacy index })+\text { Mean years at schooling })}{3}
$$

3.1 Adult literacy index

3.2 Mean years at school

$$
\text { Adult literacy Index }=\frac{(x-a)}{(b-a)}
$$

$$
\text { Mean Years at School Index }=\frac{(x-a)}{(b-a)}
$$

4. Per-capita Index

$$
\text { Adjusted GNI per capita }(\text { PPP } \$) \text { Index }=\frac{(\log x-\log a)}{(\log b-\log a)}
$$

5. Extrapolation calculation

$$
\mathbf{f}(\mathbf{x})=\sum_{\mathbf{i}=\mathbf{1}}^{\mathbf{N}} \mathbf{f}\left(\mathbf{x}_{\mathbf{i}}\right) \mathbf{p}_{\mathbf{i}}^{\mathbf{L}}(\mathbf{x})
$$

6. Mean

$$
\overline{\mathbf{x}}=\frac{\sum \mathbf{x}}{\mathbf{N}}
$$

7. Standard Deviation

$$
\sigma=\sqrt{\frac{1}{N} \sum_{i=1}^{N}(x-\mu)^{2}}
$$

8. Regression equation

$$
\mathbf{Y}=\boldsymbol{\alpha}+\boldsymbol{\beta} \mathbf{x}
$$

9. Growth

$$
\mathbf{r}=\left[\frac{\left(\mathrm{HDI}_{2011}-\mathrm{HDI}_{2006}\right)}{\mathrm{HDI}_{2006}}\right] \frac{\mathbf{1}}{\mathbf{5}}
$$

10. Time to reach at high human development threshold

$$
t=\left[\frac{\left(0.75-\text { HDI }_{2011}\right)}{\text { HDI }_{2011}}\right] \frac{1}{r}
$$

11. Time to reach at optimum level i.e. 1

$$
t=\left[\frac{\left(1-H_{2011}\right)}{H_{2011}}\right] \frac{1}{r}
$$

\section{Where}

$\mathrm{x}=$ value of given category on specific area $a=$ lowest value of given category on series $\mathrm{b}=$ highest value of given category on series $\alpha, \beta, \gamma=$ constant, determined by value of $x$ $\mathrm{Y}=\mathrm{HDI}$ value for forecasted year $\mathrm{x}=\mathrm{HDI}$ value, reported on different HDR

$\overline{\mathrm{x}}=$ mean value of HDI district

$\mathrm{N}=$ total number of district on category $\mathrm{r}=$ growth/ increment rate per Annam $\mathrm{t}=$ time required to reach $\mathrm{up}$ to high human development threshold and to reach up to top of the rank respectively

$f(x i)=$ values of function and $f(x)$ is the desired value of the function. The Lagrange polynomial PLi is the polynomial of order $\mathrm{N}-1$ that has the value 1 when $\mathrm{x}=\mathrm{xi}$ and 0 for all $\mathrm{xj}, \mathrm{i}$ 
Annex 2: Life expectancy, Education and GDP index for Province from 1996 to 2011

\begin{tabular}{|c|c|c|c|c|c|}
\hline \multirow{2}{*}{ Province } & \multicolumn{5}{|c|}{ Index value by Year } \\
\hline & 1996 & 1999 & 2001 & 2006 & 2011 \\
\hline \multicolumn{6}{|c|}{ Life Expectancy } \\
\hline 1 & 0.612 & 0.629 & 0.660 & 0.709 & 0.726 \\
\hline 2 & 0.588 & 0.631 & 0.624 & 0.638 & 0.757 \\
\hline 3 & 0.547 & 0.559 & 0.636 & 0.728 & 0.755 \\
\hline 4 & 0.530 & 0.619 & 0.653 & 0.664 & 0.730 \\
\hline 5 & 0.493 & 0.561 & 0.593 & 0.581 & 0.710 \\
\hline 6 & 0.392 & 0.462 & 0.482 & 0.509 & 0.677 \\
\hline 7 & 0.385 & 0.434 & 0.491 & 0.568 & 0.699 \\
\hline National & 0.513 & 0.561 & 0.598 & 0.636 & 0.722 \\
\hline \multicolumn{6}{|c|}{ Education } \\
\hline 1 & 0.336 & 0.446 & 0.400 & 0.445 & 0.431 \\
\hline 2 & 0.219 & 0.332 & 0.285 & 0.356 & 0.274 \\
\hline 3 & 0.288 & 0.436 & 0.388 & 0.446 & 0.405 \\
\hline 4 & 0.323 & 0.430 & 0.415 & 0.440 & 0.430 \\
\hline 5 & 0.269 & 0.411 & 0.342 & 0.423 & 0.390 \\
\hline 6 & 0.214 & 0.351 & 0.274 & 0.379 & 0.332 \\
\hline 7 & 0.261 & 0.318 & 0.304 & 0.362 & 0.351 \\
\hline National & 0.279 & 0.397 & 0.351 & 0.413 & 0.382 \\
\hline \multicolumn{6}{|c|}{ Per capita Income } \\
\hline 1 & 0.160 & 0.389 & 0.412 & 0.445 & 0.414 \\
\hline 2 & 0.197 & 0.440 & 0.391 & 0.471 & 0.365 \\
\hline 3 & 0.239 & 0.474 & 0.452 & 0.501 & 0.427 \\
\hline 4 & 0.189 & 0.360 & 0.447 & 0.460 & 0.403 \\
\hline 5 & 0.143 & 0.375 & 0.388 & 0.430 & 0.368 \\
\hline 6 & 0.123 & 0.336 & 0.382 & 0.468 & 0.349 \\
\hline 7 & 0.120 & 0.342 & 0.388 & 0.431 & 0.316 \\
\hline National & 0.169 & 0.390 & 0.411 & 0.458 & 0.383 \\
\hline
\end{tabular}


Annex 3: Input data district wise HDI values from 1996 to 2011

\begin{tabular}{|c|c|c|c|c|}
\hline \multirow{2}{*}{ Districts } & \multicolumn{4}{|c|}{ HDI value } \\
\hline & 1996 & 2001 & 2006 & 2011 \\
\hline Achham & 0.3930 & 0.3500 & 0.4430 & 0.4460 \\
\hline Agrakhachi & 0.4870 & 0.4710 & 0.5490 & 0.5400 \\
\hline Baglung & 0.4870 & 0.4920 & 0.5490 & 0.5260 \\
\hline Baitadi & 0.3930 & 0.3910 & 0.4430 & 0.4860 \\
\hline Bajhang & 0.2860 & 0.3310 & 0.4350 & 0.4300 \\
\hline Bajura & 0.2860 & 0.3100 & 0.4350 & 0.4250 \\
\hline Banke & 0.4580 & 0.4790 & 0.4810 & 0.5370 \\
\hline Bara & 0.4620 & 0.4650 & 0.4780 & 0.5190 \\
\hline Bardiya & 0.4580 & 0.4290 & 0.4810 & 0.5190 \\
\hline Bhaktapur & 0.5100 & 0.5950 & 0.6020 & 0.6180 \\
\hline Bhojpur & 0.5310 & 0.4720 & 0.5430 & 0.5370 \\
\hline Chitwan & 0.4620 & 0.5180 & 0.4780 & 0.5980 \\
\hline Dadeldhura & 0.3930 & 0.4340 & 0.4430 & 0.5030 \\
\hline Dailekh & 0.4330 & 0.3810 & 0.4480 & 0.4850 \\
\hline Dang & 0.4580 & 0.4090 & 0.4810 & 0.5370 \\
\hline Darchula & 0.2860 & 0.4240 & 0.4350 & 0.5020 \\
\hline Dhading & 0.5100 & 0.4100 & 0.6020 & 0.5240 \\
\hline Dhankuta & 0.5310 & 0.5070 & 0.5430 & 0.5700 \\
\hline Dhanusha & 0.4620 & 0.4490 & 0.4780 & 0.4870 \\
\hline Dolakha & 0.4370 & 0.4500 & 0.4540 & 0.5220 \\
\hline Dolpa & 0.3220 & 0.3710 & 0.4350 & 0.4480 \\
\hline Doti & 0.3930 & 0.4020 & 0.4430 & 0.4700 \\
\hline Gorkha & 0.4870 & 0.4540 & 0.5490 & 0.5450 \\
\hline Gulmi & 0.4870 & 0.4670 & 0.5490 & 0.5260 \\
\hline Humla & 0.3220 & 0.3670 & 0.4350 & 0.4320 \\
\hline Ilam & 0.5310 & 0.5210 & 0.5430 & 0.5780 \\
\hline Jajarkot & 0.4330 & 0.3310 & 0.4480 & 0.4550 \\
\hline Jhapa & 0.4880 & 0.4940 & 0.5190 & 0.5650 \\
\hline Jumla & 0.3220 & 0.3480 & 0.4350 & 0.4590 \\
\hline Kailali & 0.4250 & 0.4420 & 0.5030 & 0.5130 \\
\hline
\end{tabular}


Provincial Comparison of Development Status in Nepal

\begin{tabular}{|c|c|c|c|c|}
\hline \multirow{2}{*}{ Districts } & \multicolumn{4}{|c|}{ HDI value } \\
\hline & 1996 & 2001 & 2006 & 2011 \\
\hline Kalikot & 0.3220 & 0.3220 & 0.4350 & 0.4320 \\
\hline Kanchanpur & 0.4250 & 0.4630 & 0.5030 & 0.5280 \\
\hline Kapilbastu & 0.4350 & 0.4370 & 0.4680 & 0.4900 \\
\hline Kaski & 0.4870 & 0.5930 & 0.5490 & 0.6230 \\
\hline Kathamndu & 0.5100 & 0.6520 & 0.6020 & 0.6660 \\
\hline Kavre & 0.5100 & 0.5430 & 0.6020 & 0.5720 \\
\hline Khotang & 0.5310 & 0.4420 & 0.5430 & 0.5520 \\
\hline Lalitpur & 0.5100 & 0.5880 & 0.6020 & 0.6400 \\
\hline Lamjung & 0.4870 & 0.4920 & 0.5490 & 0.5070 \\
\hline Mahottari & 0.4620 & 0.4070 & 0.4780 & 0.4540 \\
\hline Makawanpur & 0.5100 & 0.4790 & 0.6020 & 0.5510 \\
\hline Manang & 0.4140 & 0.5020 & 0.4350 & 0.5520 \\
\hline Morang & 0.4880 & 0.5310 & 0.5190 & 0.5620 \\
\hline Mugu & 0.3220 & 0.3040 & 0.4350 & 0.4510 \\
\hline Mustang & 0.4140 & 0.4820 & 0.4350 & 0.5520 \\
\hline Myagdi & 0.4870 & 0.4980 & 0.5490 & 0.5520 \\
\hline Nawalparasi & 0.4350 & 0.4820 & 0.4680 & 0.5450 \\
\hline Nawalparasi & 0.4350 & 0.4820 & 0.4680 & 0.5450 \\
\hline Nuwakot & 0.5100 & 0.4630 & 0.6020 & 0.5240 \\
\hline Okhaldhunga & 0.5310 & 0.4810 & 0.5430 & 0.5290 \\
\hline Palpa & 0.4870 & 0.4860 & 0.5490 & 0.5570 \\
\hline Panthar & 0.5310 & 0.4830 & 0.5430 & 0.5520 \\
\hline Parbat & 0.4870 & 0.5040 & 0.5490 & 0.5380 \\
\hline Parsha & 0.4620 & 0.4480 & 0.4780 & 0.5220 \\
\hline Pyuthan & 0.4330 & 0.4160 & 0.4480 & 0.4760 \\
\hline Ramechhap & 0.5100 & 0.4340 & 0.6020 & 0.5320 \\
\hline Rasuwa & 0.4370 & 0.3940 & 0.4540 & 0.5200 \\
\hline Rautahat & 0.4620 & 0.4090 & 0.4780 & 0.4600 \\
\hline Rolpa & 0.4330 & 0.3840 & 0.4480 & 0.4640 \\
\hline Rukum & 0.4330 & 0.3860 & 0.4480 & 0.4910 \\
\hline Rukum & 0.4330 & 0.3860 & 0.4480 & 0.4910 \\
\hline
\end{tabular}


Provincial Comparison of Development Status in Nepal

\begin{tabular}{lcccc}
\hline \multirow{2}{*}{ Districts } & \multicolumn{3}{c}{ HDI value } \\
\cline { 2 - 4 } & 1996 & 2001 & 2006 & 2011 \\
\hline Rupendehi & 0.4350 & 0.5460 & 0.4680 & 0.5490 \\
Salyan & 0.4330 & 0.3990 & 0.4480 & 0.5050 \\
Sankhuwasava & 0.4240 & 0.4810 & 0.5190 & 0.5460 \\
Saptari & 0.4880 & 0.4530 & 0.5190 & 0.4980 \\
Sarlahi & 0.4620 & 0.4080 & 0.4780 & 0.4690 \\
Sindhuli & 0.5100 & 0.4690 & 0.6020 & 0.5040 \\
Sindhupalchowk & 0.4370 & 0.4140 & 0.4540 & 0.5140 \\
Siraha & 0.4880 & 0.4270 & 0.5190 & 0.4740 \\
Solukhumbu & 0.4240 & 0.4790 & 0.5190 & 0.5580 \\
Sunsari & 0.4880 & 0.5000 & 0.5190 & 0.5700 \\
Surkhet & 0.4330 & 0.4860 & 0.4480 & 0.5400 \\
Syanja & 0.4870 & 0.5350 & 0.5490 & 0.5790 \\
Tanahu & 0.4870 & 0.5240 & 0.5490 & 0.5060 \\
Taplajung & 0.4240 & 0.4670 & 0.5190 & 0.5450 \\
Terhathum & 0.5310 & 0.5230 & 0.5430 & 0.5750 \\
Udayapur & 0.5310 & 0.4880 & 0.5430 & 0.5330 \\
\hline Total & 0.4513 & 0.4537 & 0.5024 & 0.5220 \\
\hline
\end{tabular}

